\title{
The examination and identification of bite marks in foods using 3D scanning and 3D comparison methods
}

\author{
Silvio Naether • Ursula Buck • Lorenzo Campana • \\ Robert Breitbeck $\cdot$ Michael Thali
}

Received: 1 July 2010 /Accepted: 2 May 2011 /Published online: 24 May 2011

(C) Springer-Verlag 2011

\begin{abstract}
Bite mark analysis offers the opportunity to identify the biter based on the individual characteristics of the dentitions. Normally, the main focus is on analysing bite mark injuries on human bodies, but also, bite marks in food may play an important role in the forensic investigation of a crime. This study presents a comparison of simulated bite marks in different kinds of food with the dentitions of the presumed biter. Bite marks were produced by six adults in slices of buttered bread, apples, different kinds of Swiss chocolate and Swiss cheese. The time-lapse influence of the bite mark in food, under room temperature conditions, was also examined. For the documentation of the bite marks and the dentitions of the biters, 3D optical surface scanning technology was used. The comparison was performed using two different software packages: the ATOS modelling and analysing software and the 3D studio max animation software. The ATOS software enables an automatic computation of the deviation between the two meshes. In the present study, the bite marks and the dentitions were compared, as well as the meshes of each bite mark which were recorded in the different stages of time lapse. In the 3D studio max software, the act of biting was animated to compare the dentitions with the bite mark.
\end{abstract}

Electronic supplementary material The online version of this article (doi:10.1007/s00414-011-0580-7) contains supplementary material, which is available to authorized users.

S. Naether $(\bowtie) \cdot U$. Buck $\cdot$ L. Campana $\cdot$ R. Breitbeck $\cdot$ M. Thali Institute of Forensic Medicine, University of Bern,

IRM-Buehlstrasse 20,

3012 Bern, Switzerland

e-mail: silvio.naether@irm.unibe.ch

S. Naether $\cdot$ U. Buck

Canton Police Bern, Accident service,

Schermenweg 9,

3001 Bern, Switzerland
The examined food recorded the individual characteristics of the dentitions very well. In all cases, the biter could be identified, and the dentitions of the other presumed biters could be excluded. The influence of the time lapse on the food depends on the kind of food and is shown on the diagrams. However, the identification of the biter could still be performed after a period of time, based on the recorded individual characteristics of the dentitions.

Keywords Forensic science · Forensic odontology · Bite mark analysis $\cdot 3 \mathrm{D}$ optical scanning $\cdot 3 \mathrm{D}$ match analysis . Virtopsy

\section{Introduction}

Bite marks may play a valuable role in the forensic investigation of a crime. Bite marks, which are analysed by forensic experts, mostly appear on skin [1], but they also can be represented on objects, for example on food.

There are two basic assumptions in bite mark analysis. The first assumption is that the dentitions of the individuals are unique with respect to the position, shape, size and pattern, and the second one is that the bite mark represents these characteristics with sufficient detail to enable a comparison [2-6].

The action of biting is a dynamic procedure due to the movement of the maxilla and the mandible of the biter and the reaction of the bitten person. The skin has also varying biomechanical properties, depending on the anatomic location $[7,8]$.

These possible wounding dynamics of bite marks on skin and the distortion created by the reaction of the bitten person, that aggravate the match analysis, are normally not present in bite marks in food because food does not have 
the problematic varying biomechanical properties like skin. The different consistencies of food and the shrinkage and putrefaction caused by time lapse are influencing factors which have to be taken into consideration in the 3D match analysis.

In some cases, the identification of bite marks in food can be of great importance $[9,10]$. This study was performed to evaluate the identification of bite marks in different kinds of food. Furthermore, it was investigated whether the identification of the biter is still possible, even when the food has been lying around for several days or weeks, before it was found.

As mentioned in recent studies, the third dimension is very important for the bite mark analysis [11-15], especially in cases of bite marks in food, because the impression of the dentitions in food cannot be reduced to two dimensions without the loss of information [16].

In the present study, we simulated bite marks in different kinds of food by six adults. The dental casts of these suspects as well as the bite marks were digitized using $3 \mathrm{D}$ surface scanning and were compared in 3D using computer software. The scan of each bite mark in food and the comparison were repeated after days, after weeks and after months in order to investigate the alteration of bite marks in food and the possibility of identifying the biter after the passing of time.

\section{Materials and methods}

For the study, the six adults produced bite marks each in different kinds of food: a slice of buttered bread, an apple, Swiss chocolate (Toblerone and a bar of milk chocolate) and Swiss cheese (Emmental) (Online Resource 1.1). A forensic dentist constructed the dental casts of the maxilla and mandible of each biter.

The dental casts and the food displaying the bite marks were digitized using a 3D optical surface scanner. To capture the surface of the cheese and buttered bread by means of optical surface scanning, the food had to be covered with a thin white layer to decrease the reflection factor of the surface. Therefore, we applied and compared four different kinds of spray on cheese after a period of 2 weeks: Developer U89 (Helling GmbH, Hamburg, Germany), MR 2000 Anti-Reflex L aerosol spray (MR ${ }^{\circledR}$ Chemie GmbH, Unna, Germany), Tevlin chalk spray (Technischer Vertrieb Ulrich Lippert, Murrhardt, Germany) and alcohol mixed with KRONOS titanium dioxide applied by an airbrush (Graphiti $\mathrm{GmbH}$, Braunschweig, Germany). The alcohol mixture applied by an airbrush in contrast to the other sprays did not influence the food surface, and the thin white layer was visible after several months (Online Resource 1.2).

The scan of the food was repeated after 1 day, 5 days, 2 weeks, 4 weeks and 7 months. The food was stored at room temperature, which varied between 15 and $30^{\circ} \mathrm{C}$ during the day and night-time and without covering. The humidity was about $50 \%$.

The 3D models of each bite mark in food, digitized in the different stages of time lapse, were compared with the dentitions of the suspected biters using the ATOS software and 3D studio max software. After 7 months, DNA samples from the bite marks in buttered bread, chocolate and cheese were taken and analysed.

\section{D surface scanning}

The three-dimensional documentation of the objects was performed by using the GOM ATOS 3D surface scanning system (www.gom.com, Braunschweig, Germany). In the Virtopsy ${ }^{\circledR}$ approach, this technology is applied for the 3D documentation of the body surface, including all external injuries and for the digitalization of injury-inflicting objects, for example tools, weapons or accidental vehicles [17-19] (www.virtopsy.com).

This optical scanning system is based on the triangulation principle. A projector unit projects a fringe pattern onto the surface of the object, which is recorded by two CCD cameras mounted on both sides of the projector (Online Resource 1.3). Within seconds, the software calculates high-precision 3D coordinates of up to 4 million surface points.

The point spacing depends on the measuring volume used. For the scanning of the food we applied, the ATOS III digitizer using a measuring volume of $150 \times 150 \times 150 \mathrm{~mm}$ with a resulting point spacing of $0.07 \mathrm{~mm}$. For the dentitions, the ATOS II SO set-up with a measuring volume of $65 \times 50 \times 30 \mathrm{~mm}$ with a resulting point spacing of $0.05 \mathrm{~mm}$ was used. The scanning was performed by placing the objects on an automated rotation table. After the first measurement, the table rotates $15^{\circ}$, and the next scan starts automatically. This is continued until the whole object is captured. The software automatically merges the single measurements into a single data set using reference targets which are stuck around and on the object.

Polygon meshes (3D models) of the dentitions and of the bite marks are created in the ATOS software (Online Resource 1.4; Fig. 1).

For the comparison of the dentitions with the bite marks, two different software products were applied: the ATOS modelling software and the 3D studio max animation software. For the import of the 3D models into the 3D studio max, the polygon meshes are thinned based on the curvatures and saved as stereolithography files.

3D comparison using ATOS software

These resolved accurate true-to-scale 3D models of the bite marks, documented after the different time lapses, and the 
Fig. 1 Polygon meshes of the bite marks in different kinds of food. a Slice of buttered bread. b Swiss cheese. c Apple. d Bar of milk chocolate

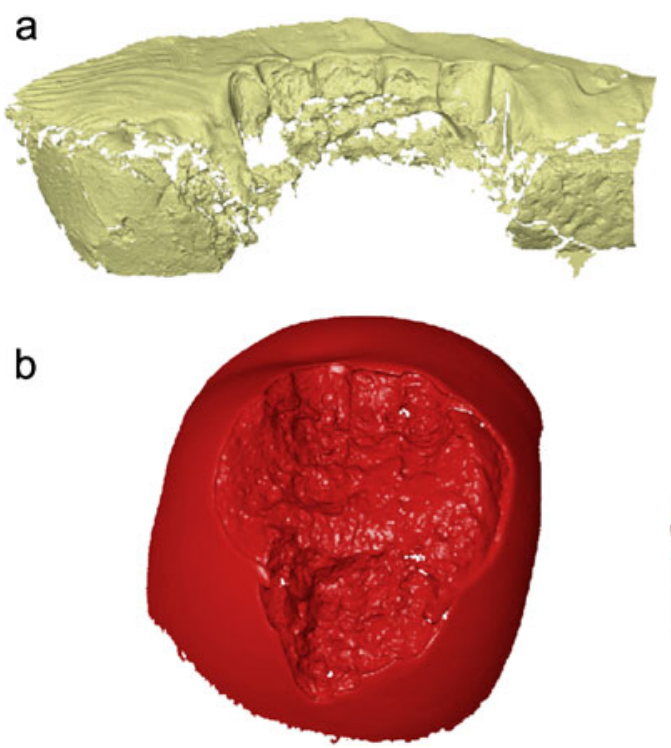

C

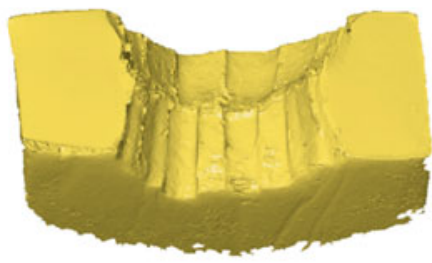

d

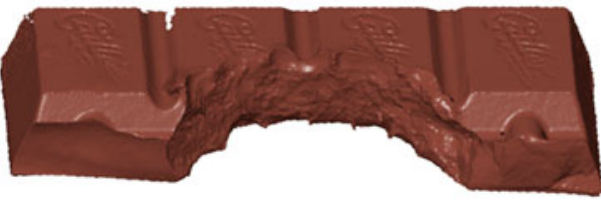

dentitions were compared using the ATOS software. The meshes of the maxilla and mandible were transformed into the corresponding positions of the bite mark. This allows for conclusions about the correspondence of the dentition to the bite mark (Online Resource 1.5). In this 3D patternassociated comparison, the structure of several teeth, as well as the relationship to the surrounding teeth was compared. In case of shrinking of the food because of the time between the biting act and the documentation, the 3D models were scaled with the shrinking factor to compare with the teeth.

Apart from the comparison of the bite marks with the dentitions, a comparison of each bite mark was performed in the different stages of time lapse. Therefore, the different meshes of one bite mark were scaled (if necessary) and transformed into the corresponding position using a "best fit registration" which is automatically calculated by the software. The amount of deviation of two meshes is computed and displayed as a colour-coded polygon mesh (Fig. 2a, b, c). A colour scale represents the amount of deviation. The calculated scale factor represents the value of shrinking. After 7 months, it is even possible to see the shrinking of cheese by positioning the polygon mesh side by side (Fig. 2d).

\section{$3 \mathrm{D}$ comparison using $3 \mathrm{D}$ studio max}

In the 3D studio max software, the comparison is performed by simulating the biting act. The $3 \mathrm{D}$ models of the maxilla and mandible are moved into the position of the first contact of the teeth with the food. Then, the act of biting is animated based on the corresponding features of the bite mark with the dentitions (Fig. 3; Online Resource 1.6). This animation can be run at different speeds, as well as in reverse. To compare the dentitions with the bite marks, the animation is shown from different views, and the opacity of the models is adjusted.

\section{Results}

Comparison of the bite marks in food with the dentitions

Each bite mark was compared with the dentitions of the suspected biters. In all the cases, the biter could be identified, and the dentitions of the other suspected could be excluded (Fig. 4; Online Resource 1.5 to 1.8). In the cheese and chocolate, an average of six teeth of the maxilla and seven teeth of the mandible could be compared with the dentitions. In the buttered bread, an average of 6 teeth of the maxilla could be compared; a comparison of the mandible was not possible. In the apple, five teeth of the maxilla and six teeth of the mandible could be matched with the dentitions of the suspect (Table 1).

Change of the bite marks in food caused by the passing of time

In chocolate, no changes were visible. The cheese had shrivelled after 5 days about $4 \%$, after 2 weeks about $8 \%$, after 4 weeks about $10 \%$ and after 7 months about $11 \%$. The bite mark in the buttered bread had shrivelled, after 1 day about $7 \%$, after 5 days about $12 \%$, after 2 weeks about $15 \%$ and after 4 weeks about $15 \%$. The apples could not be examined after a week or longer because of the advanced putrefaction (Fig. 5).

Results of the match analysis due to the changes caused by the passing of time

After the scaling of the models with the analysed factor, the comparison could be performed, and the same number of teeth could be matched to the dentitions of the biter (Fig. 5). The individual shape of the dentitions on the bite mark was 

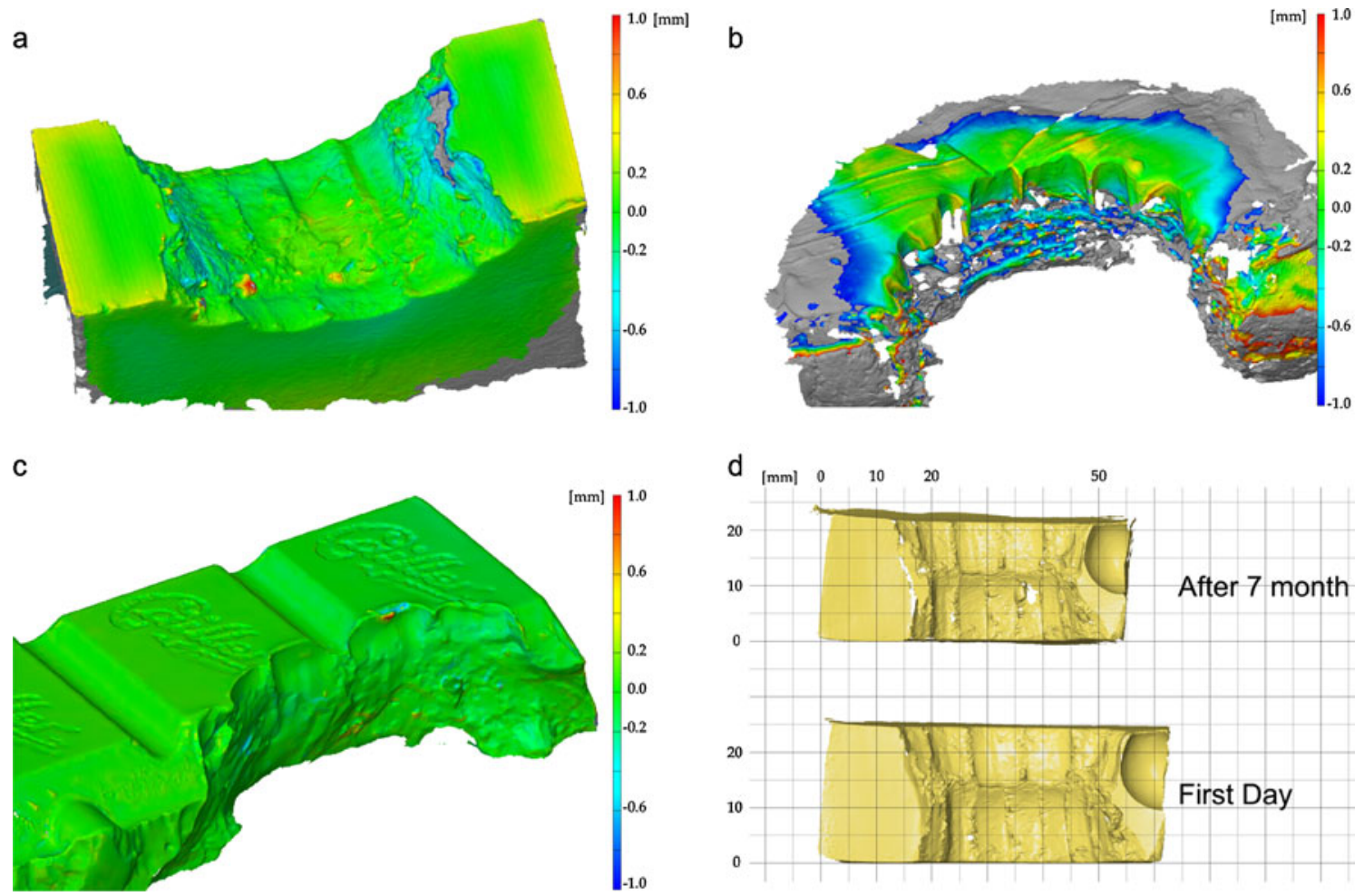

Fig. 2 Automatic comparison of bite marks after different stages of time lapse. The amount of deviation is displayed as a colour-coded polygon mesh. a Nearly no deviation between the bite mark in cheese digitized at the first day and 2 weeks later, after scaling of $8 \%$. b The green colour represent that there is nearly no deviation between the bite mark in the butter layer of the buttered bread between the 3D

model of the first day and that after 2 weeks, which is scaled $15 \%$. c The 3D model of bite mark in chocolate, digitized at the first day is identical with that which was digitized after 7 months. No scaling was necessary. d Comparison of the different stages of time lapse of the cheese by positioning side by side without scaling

also visible after the time lapse. The result and the quality of the 3D match analysis were not influenced by the changes caused by the passing of time. The identification of the biter was in all cases possible even after a time lapse of 7 months.

Results of the DNA analysis of the samples taken from the bite marks in foodstuffs

The identification of the biter of the bite mark in cheese, as well as in the buttered bread was possible in two of the six

cases. In the case of the bite mark in chocolate, all the biters could be identified.

\section{Discussion}

Bite marks produced in a firm substrate, for example food, may display more characteristic features than bite marks inflicted on a highly deformable substrate such as skin.

The results of the study indicated that the examined foods (slices of buttered bread, apples, chocolate and

Table 1 Amount of matched teeth

\begin{tabular}{|c|c|c|c|c|c|c|c|c|c|c|c|c|}
\hline \multirow[t]{2}{*}{ Subject } & \multicolumn{2}{|l|}{ Blue } & \multicolumn{2}{|l|}{ Green } & \multicolumn{2}{|l|}{ Red } & \multicolumn{2}{|c|}{ Yellow } & \multicolumn{2}{|l|}{ White } & \multicolumn{2}{|c|}{ Magenta } \\
\hline & Mand & Max & Mand & Max & Mand & Max & Mand & Max & Mand & Max & Mand & $\operatorname{Max}$ \\
\hline Apple & 4 & 4 & 4 & 4 & 3 & 5 & 5 & 5 & 4 & 5 & 4 & 4 \\
\hline Buttered bread & 0 & 7 & 0 & 8 & 0 & 5 & 0 & 8 & 0 & 6 & 0 & 7 \\
\hline Cheese & 7 & 5 & 5 & 4 & 6 & 5 & 6 & 6 & 6 & 6 & 6 & 6 \\
\hline Chocolate & 7 & 5 & 6 & 6 & 7 & 5 & 6 & 5 & 7 & 5 & 6 & 5 \\
\hline
\end{tabular}

Mand mandible, Max maxilla 
a

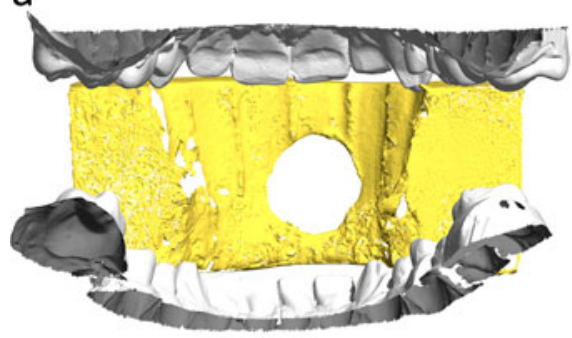

d

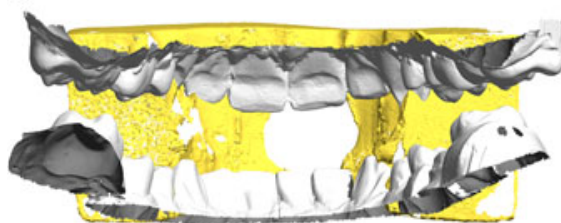

b

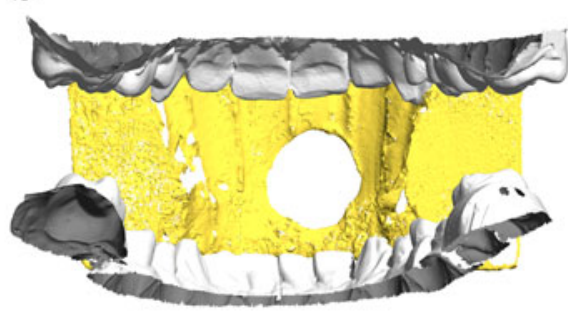

e

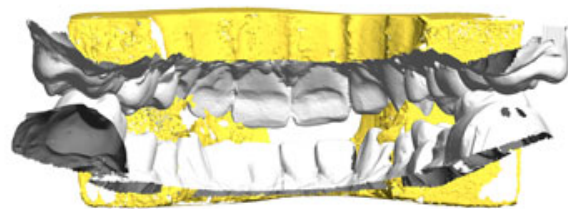

C

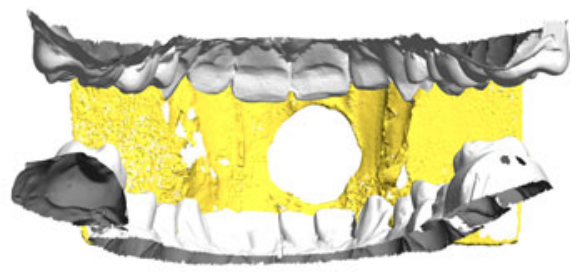

f

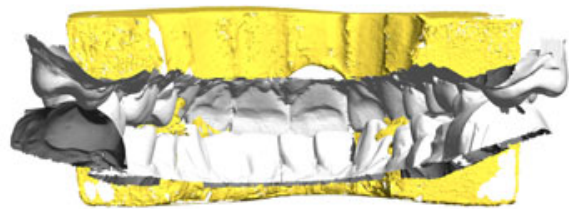

Fig. 3 Visualization of the different sequences of the biting act (a-f) from a back view

cheese), have good properties to record the position, shape, size and pattern of dentitions. Bite marks in chocolate and cheese, especially, clearly displayed characteristic features of teeth which were important for identification. Not only the tip of the tooth, but almost the incisal surface of the complete tooth, was visible in the impressions, depending on the thickness of the slices of chocolate or cheese.
As described in Bernitz et al. [16], the movement of the mandible during the biting act produced longer bite marks with the frequent presence of scratch marks, than that of the maxilla. This effect was visible especially in cheese and chocolate.

The bite marks in all examined kinds of food were compared with the dentitions of the presumed biter. The
Fig. 4 A 3D comparison of the bite mark in the apple with the dentitions of the suspected biters using ATOS software. a The grey mandible does not match the bite mark, which is visualized in a $3 \mathrm{D}$ view. $\mathbf{b}$ In the profile cut line, it is clearly visible that the grey dentitions does not match the bite mark. c The green mandible matches the bite mark, which is visualized in a $3 \mathrm{D}$ view. d Visualization of the match with the green dentitions in a profile cut line. $\mathbf{e}-\mathbf{f}$ Match of the front teeth of the green maxilla with the bite mark, visualized in a $3 \mathrm{D}$ view
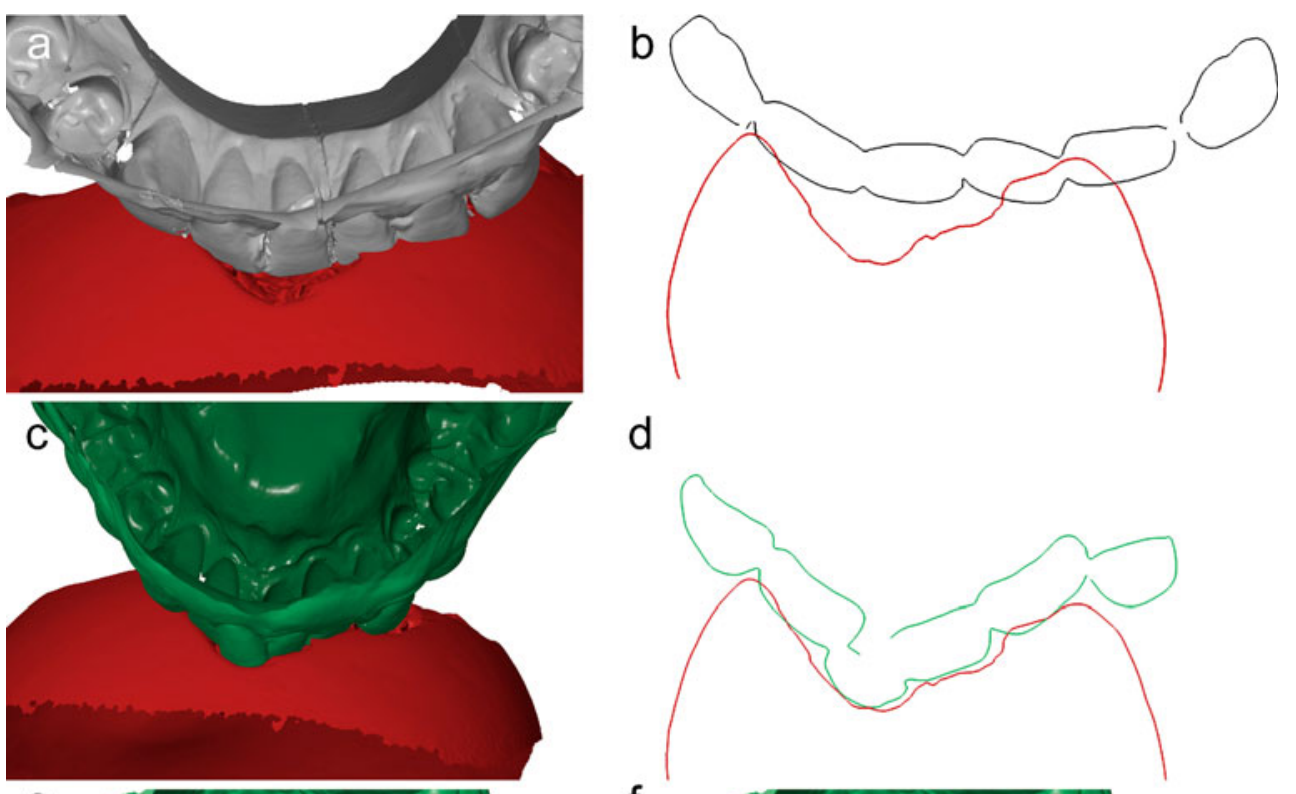

d

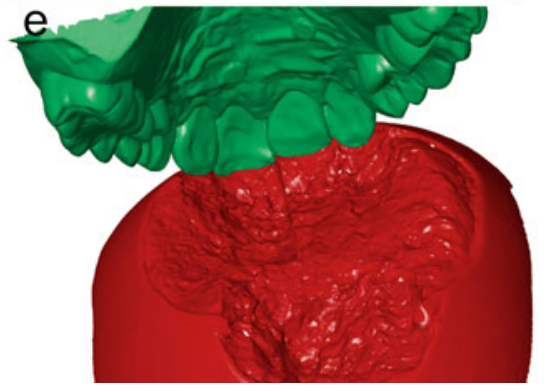

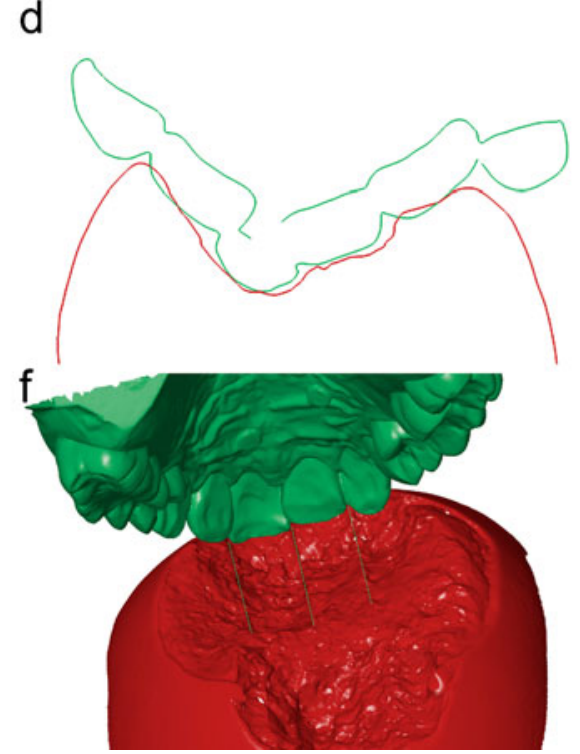




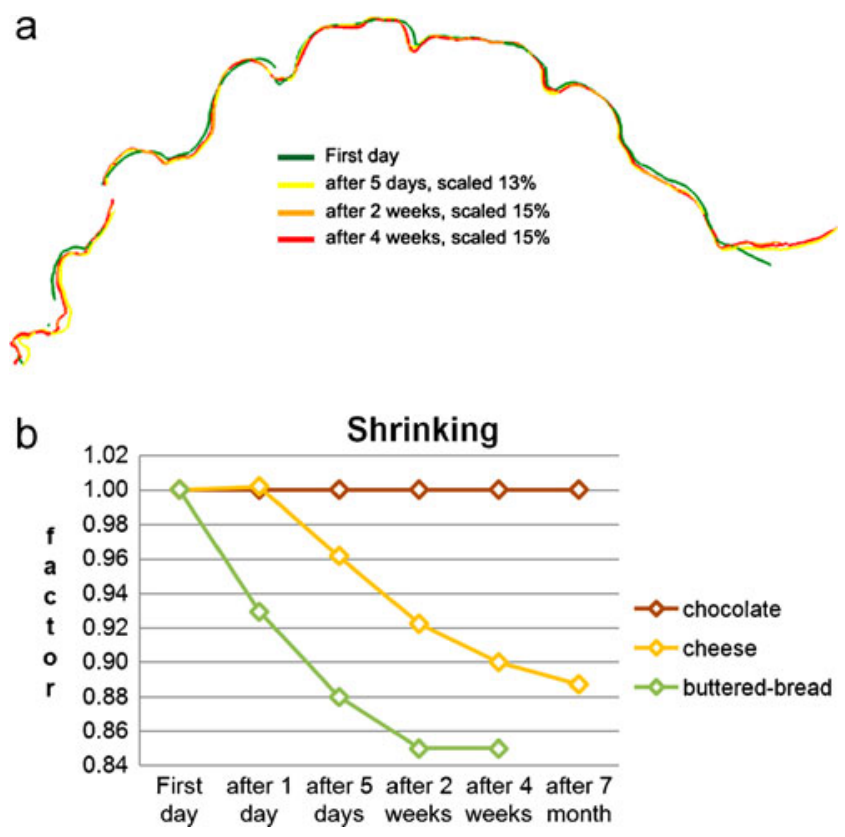

Fig. 5 a Comparison of the sections through a bite mark in buttered bread digitized at different time lapse after scaling. b Graphic of the shrinking factor of the tested food

biter of each bite mark could be identified. A second expert repeated the whole bite mark comparison independently. In all cases, both experts achieved the same results.

Furthermore, the comparison of each bite mark with the identical bite mark recorded in the different stages of time lapse was performed to evaluate the influence of the passing of time on food. This influence varied depending on the kind of food with their different characteristics used. The chocolate was not influenced by the passing of time. The cheese had shrivelled after 5 days about 4\%, after 2 weeks about $8 \%$, after 4 weeks about $10 \%$ and after 7 months about $11 \%$ because of the loss of moisture and oils. The comparison of the dentitions with the bite marks in the cheese after a time lapse of 7 months was still possible based on the individual characteristic features which the bite marks in the cheese displayed. In our case, the apples, which were stored at room temperatures between 25 and $35^{\circ} \mathrm{C}$, could not be examined after 1 week because of the advanced putrefaction. After 2 days, the deviations between the apple bite marks were only minimal, and thus, the comparison was still successful. The time period, in which the bite marks in the apples can be examined, depends on the characteristics of the different types of apple and the storage conditions. The slices of buttered bread could be analysed until they were disposed because of the moulds.

The documentation of bite marks and dentitions using a 3D scanner is very important for the bite mark analysis as mentioned in recent studies of Martin-de las Heras, Blackwell and Thali $[11-15]$. The results of this study proved that $3 \mathrm{D}$ optical surface scanning is a suitable method for the documentation of bite marks and dentitions. The 3D models of the scanned objects display high resolution and accuracy, including all fine detail. The 3D optical surface scanner is easy to use; the scanning process is time saving and can be partly automated by the use of an automatic rotation table.

Furthermore, in contrast to the traditional methods and scanning electron microscopy [20], this method is nondestructive. After the surface scanning of the bite mark, DNA samples can be taken. The collection of DNA possibly destroys features of the bite mark, and an analysis using the casting method would no more be possible. The highly reliable DNA analysis remains the method of choice, and the $3 \mathrm{D}$ bite mark documentation cannot equal it at present [21]. However, when using the 3D surface scanning method, both identification methods can be performed in combination. In the present study, the identification using DNA analysis after the time lapse of 7 months was only successful in $56 \%$ of the cases.

The comparison, using the ATOS software, enables an automatic computation of the deviation between the two meshes, for example, between the meshes of each bite mark, scanned in different time lapses. The deviation between the meshes is represented by a colour-coded polygon mesh. Thus, the ATOS software allows an easy and very accurate analysis and interpretation of the results.

In the 3D studio max software, the act of biting was animated to compare the dentitions with each bite mark. This allows for a dynamic comparison during the act of biting. The 3D match or non-match is clearly visible in an upside down view or if one mesh is displayed with reduced opacity.

The acquisition and the electronic storage of the fullscale surface of the bite marks in food allows for examination at any time using the computer. Data exchange between investigating authorities at national and international levels can be effected easily with electronic data carriers. The results of the 3D pattern-associated comparison with the alleged dentitions can be presented as a demonstrative expertise for justice.

The equipment for surface scanning is still expensive, but the method is also very useful for other areas in the work of the police and forensic medicine institutions [19, 22-25]. Cooperation between these institutions may make it possible to afford such technology and improve the investigations in the complete forensic field, not just in bite mark analyses.

\section{Conclusion}

Food is a good medium for bite mark analysis. The identification of a suspect, based on bite marks in food is possible even when the food has been left for weeks or 
months under room temperature conditions. The optical surface scanning and $3 \mathrm{D}$ computer-assisted comparison is a non-destructive, accurate and efficient method for bite mark analyses.

Acknowledgements The authors thank Steffen Ross and Matthias Voisard for their help in the data collection. Many thanks also to Lowri Jones for her great support for language consultation.

\section{References}

1. Senn DR, Stimson PG (2010) Forensic dentistry, 2nd edn. CRC Press, Boca Raton, pp 332-337

2. Pretty IA (2008) Forensic dentistry: 2. Bitemarks and bite injuries. Dent Update 35(1):48-50, 53-4,57-8 passim

3. Pretty IA (2007) Development and validation of a human bitemark severity and significance scale. J Forensic Sci 52(3):687-691

4. Pretty IA (2006) The barriers to achieving an evidence base for bitemark analysis. Forensic Sci Int 159(suppl 1):110-120

5. Miller RG, Bush PJ, Dorion RBJ, Bush MA (2009) Uniqueness of the dentition as impressed in human skin: a cadaver model. J Forensic Sci 54(4):909-913

6. Bush MA, Bush PJ, Sheets HD (2010) Similarity and match rates of the human dentition in three dimensions: relevance to bitemark analysis. Int J Leg Med. doi:10.1007/s00414-010-0507-8

7. Sheasby DR, MaxDonald DG (2001) A forensic classification of distortion in human bite marks. Forensic Sci Int 122:75-78

8. Bush MA, Thorsrud K, Miller RG, Dorion RBJ, Bush PJ (2010) The response of skin to applied stress: investigation of bitemark distortion in a cadaver model. J Forensic Sci 55(1):71-76

9. Layton JJ (1996) Identification from a bite mark in cheese. Forensic Sci Soc 6:76-80

10. Cameron JM, Sims BG (1974) Forensic dentistry. Churchill Livingstone, Edinburgh, pp 134-135

11. Blackwell SA, Taylor RV, Gordon I, Ogleby CL, Tanijiri T, Yoshino M, Donald MR, Clement JG (2007) 3-D imaging and quantitive comparison of human dentitions and simulated bite marks. Int J Leg Med 121:9-17

12. Martin-de las Heras S, Valenzuela A, Ogayar C, Eng M, Valverde AJ, Torres JC (2005) Computer-based production of comparison overlays from $3 \mathrm{D}$-scanned dental casts for bite mark analysis. J Forensic Sci 50(1):127-133

13. Martin-de las Heras S, Valenzuela A, Valverde AJ, Torres JC, Luna-del-Castillo JD (2007) Effectivenes of comaprison overlays generated with dental print ${ }^{\circledR}$ software in bite mark analysis. J Forensic Sci 52(1):151-156

14. Martin-de las Heras S, Tafur D (2009) Comparison of simulated human dermal bitemarks possessing three-dimensional attributes to suspected biters using a proprietary three-dimensional comparison. Forensic Sci Int 190:33-37

15. Thali MJ, Braun M, Markwalder TH, Brueschweiler W, Zollinger U, Malik NJ, Yen K, Dirnhofer R (2003) Bite mark documentation and analysis: $3 \mathrm{D} / \mathrm{CAD}$ supported photogrammetry approach. Forensic Sci Int 135:115-121

16. Bernitz H, Piper SE, Solheim T, Van Niekerk PJ, Swart TJP (2000) Comparison of bitemarks left in foodstuffs with models of the suspects dentitions as a means of identifying a perpetrator. $\mathrm{J}$ For Odontostomatol 18:27-31

17. Thali MJ, Braun M, Dirnhofer R (2003) Optical 3D surface digitizing in forensic medicine: $3 \mathrm{D}$ documentation of skin and bone injuries. Forensic Sci Int 137(2-3):203-208

18. Thali MJ, Braun M, Buck U, Aghayev E, Jackowski C, Vock P, Sonnenschein M, Dirnhofer R (2005) VIRTOPSY — scientific documentation, reconstruction and animation in forensic: individual and real 3D data based geo-metric approach including optical body/object surface and radiological CT/MRI scanning. J Forensic Sci 50(2):428-442

19. Thali MJ, Dirnhofer R, Vock P (2008) The virtopsy approach 3D optical and radiological scanning and reconstruction in forensic medicine. CRC Press D4:405-409

20. Solheim T, Leidal TI (1975) Scanning electron microscopy in the investigation of bite marks in foodstuffs. Forensic Sci 6:205-215

21. Sweet D, Hildebrand D (1999) Saliva from cheese bite yields DNA profile of burglar: a case report. Int J Leg Med 112:201-203

22. Buck U, Naether S, Braun M, Bolliger S, Friederich H, Jackowski C, Aghayev E, Christe A, Vock P, Dirnhofer R, Thali MJ (2007) Application of $3 \mathrm{D}$ documentation and geometric reconstruction methods in traffic accident analysis: with high resolution surface scanning, radiological MSCT/MRI scanning and real data based animation. Forensic Sci Int 170:20-28

23. Naether S, Buck U, Bernhard W, Zingg C, Thali MJ (2008) Noncontact documentation of physical characteristics of ecstasy tablet, hemp coins, and imprint punches by using 3D optical surface scanning. Can Soc For Sci 41(4):191-198

24. Buck U, Albertini N, Naether S, Thali MJ (2007) 3D documentation of footwear impressions and tyre tracks in snow with high resolution optical surface scanning. Forensic Sci Int 171(23):157-164

25. Buck U, Naether S, Braun M, Thali MJ (2008) Haptics in forensics. The possibilities and advantages in using the haptic device for reconstruction approaches in forensic science. Forensic Sci Int 180(2-3):86-92 